\title{
Non-Extractive Spectrophotometric Determination of cu (Ii) Using 2-Hydroxy-3-Methoxy Benzaldehyde Thiosemicarbazone (Hmbatsc)
}

\author{
I. Sreevani ${ }^{1}$ and M.Swetha ${ }^{2}$ \\ ${ }^{1,2}$ Department of Chemistry, KSRM Engineering College, Kadapa-516002, India.
}

\begin{abstract}
A highly sensitive and selective spectrophotometric method was developed for the determination of trace amount of copper (II) in aqueous DMF medium. The copper ion forms a light green colored complex with 2-Hydroxy-3-Methoxy benzaldehyde thiosemicarbazone (HMBATSC) in an acidic buffer of pH 5.0. The complex has an absorbance maximum at 395nm, was stable for more than 48 hours. The complex shows maximum absorbance at $395 \mathrm{~nm}$. Beer's law is obeyed in the range 0.254- $2.542 \mu \mathrm{gml}^{-1}$. The molar absorptivity and sandell's sensitivity of the proposed method were found as $6.0 \times 10^{3} \mathrm{L.mol}^{-1} \mathrm{~cm}^{-1}$ and $0.011 \mu \mathrm{gcm}^{-2}$ respectively. The light green colored complex has 1:1 (Cu (II) - HMBATSC) Stoichiometry .The stability constant of the complex was determined as $12.306 \times 10^{5}$ by Job's method. A sensitive and selective second order derivative spectrophotometry has also been proposed for the determination of $\mathrm{Cu}(I I)$. The interference of various cations and anions were studied. The developed methods were successfully employed in the determination of $\mathrm{Cu}(\mathrm{II})$ in water and real samples.
\end{abstract}

Keywords: HMBATSC, Determination of Cu(II), Spectrophotometry.

\section{Introduction}

Copper is a red colored metal, with high electrical and thermal conductivity. It is an important transition element. It occurs in its compounds mostly in +2 oxidation state and to a lesser extent in +1 state. It is an essential element for all organisms. Being a constituent of enzymes, which catalyze oxidation reactions in a variety of metabolic pathways, several copper containing proteins have been identified in biological processes (eg. hemocyanine, cytochrome oxidase etc.).

Copper in more than $2 \mathrm{mg} / \mathrm{L}$ in drinking water can cause mental illness which is referred as Wilson's disease. In addition; studies have found that people with mental illness such as schizophrenia had increased levels of copper in their systems. However, it is unknown at this stage whether the copper contributes to the mental illness. Whether the body attempts to store more copper in response to the illness, or whether the high levels of copper are the result of mental illness, is still to be established.

Copper in the blood exists in two forms; bound to ceruloplasmin (85-95\%) and the rest in free copper loosely bound to albumin and small molecules. Free copper causes toxicity as it generates reactive oxygen species such as superoxides, hydrogen peroxides and hydroxyl radical. These damage proteins, lipids and DNA [1].Marezenko [2-3] and Snell [4] have listed variety of organic ligands for the spectrophotometric determination of copper. Extensive literature is available [5-11] on the trace determination of copper makes it the most extensively analyzed element. $\mathrm{Cu}$ (II) forms more stable, soluble or insoluble complexes with number of organic reagents. Making use of these metal chelates, number of spectrophotometric methods has been developed for the determination of copper [11-22].

In the present method HMBATSC reacts with $\mathrm{Cu}$ (II) forming a light green coloured $[\mathrm{Cu}$ (II)HMBATSC] soluble complex in the $\mathrm{pH}$ range of 4.0-6.0. The colour is stable for more than 48 hours. Hence, a detailed study of the system was under taken with a view to develop a new spectrophotometric method for the determination of $\mathrm{Cu}$ (II).

Apparatus

\section{Materials And Methods}

The absorbance measurements were made on Shimadzu UV-visible spectrophotometer (Model UV160A). $\mathrm{pH}$ measurements were made using ELICO pH meter Model L1-613 ELICO Private Limited, Hyderabad, India.

\section{Reagents \& chemicals}

All the reagents and chemicals used in the present studies were of analytical grade.

Preparation of ligand: $0.1 \mathrm{M}$ solution of HMBATSC in dimethyl formamide was employed in the present studies. 
Preparation of Metal solution: $0.1 \mathrm{M}$ stock solution of copper sulphate was prepared with distilled water and then standardized iodometrically [23].

Preparation of Buffer solutions: Other metal ion solutions were prepared from their nitrates or chlorides. Buffer solutions were prepared by mixing appropriate volumes of $1 \mathrm{M} \mathrm{CH}_{3} \mathrm{COOH}$ and $1 \mathrm{M} \mathrm{HCl},(\mathrm{pH} 1.0-3.5)$ $\mathrm{CH}_{3} \mathrm{COOH}$ and $\mathrm{CH}_{3} \mathrm{COONa}(\mathrm{pH} 4.0-7.0) \mathrm{NH}_{4} \mathrm{OH}$ and $\mathrm{NH}_{4} \mathrm{Cl}(\mathrm{pH}$ 8.0-10).

\section{Synthesis Of Ligand}

The reagent (HMBATSC) is prepared by sah and daniels [24] procedure. 11.25gms of 2-hydroxy-3methoxy benzaldehyde (I) and 4.55gms of thiosemicarbazide (II) are dissolved in sufficient volume of methanol and the mixture refluxed for 60 minutes. The contents are allowed to cool and the product separated by filtration. A crude sample (yield $80 \%$ ) is obtained $\left(\mathrm{C}_{9} \mathrm{H}_{11} \mathrm{O}_{2} \mathrm{SN}_{3}\right)$. The resultant product is recrystallized twice from hot methanol. Pure light yellowish green crystals of 2-hydroxy-3-methoxy benzaldehyde thiosemicarbazone (HMBATSC) (III) with melting point $220-225^{\circ} \mathrm{C}$ are obtained.<smiles>COc1cccc(C=O)c1O</smiles><smiles>NNC(N)=S</smiles>

II<smiles>COc1cccc(/C=N/NC(N)=S)c1O</smiles>

III

\section{Experimental Procedure}

Aliquots of solutions containing copper (II) were transferred into a series of $10 \mathrm{ml}$ volumetric flasks. To these HMBATSC $\left(4 \times 10^{-4}\right)$ was added and the contents were diluted to the mark with distilled water and mixed well. The absorbance was measured at $395 \mathrm{~nm}$ against the reagent blank. The calibration graph was constructed by plotting the absorbance against the concentration of $\mathrm{Cu}$ (II) ions. For the solutions as prepared above, the second derivative spectra were recorded with reference to the reagent blank in the wavelength range 380$520 \mathrm{~nm}$. The second derivative amplitudes were measured at wavelength $428 \mathrm{~nm}$ and were plotted against the amount of copper (II) to obtain the calibration plot.

\section{Results And Discussion}

The reaction of HMBATSC with $\mathrm{Cu}$ (II) at room temperature gives a green colored soluble complex. The absorption spectrum of [Cu (II) - HMBATSC] shows maximum absorbance at 395nm where the reagent blank does not absorb appreciably, shown in Fig 1. Therefore, subsequent analytical studies were carried out at $395 \mathrm{~nm}$ using the reagent blank. The preliminary investigations indicate the absorbance of the complex is maximum and stable in $\mathrm{pH}$ range of 4.5-5.5. Therefore, $\mathrm{pH} 5.0$ was selected for further studies. The minimum amount of reagent acquired maximum color intensity with a given amount of $\mathrm{Cu}$ (II) was evaluated from the absorbance measurements of the experimental solutions containing different amount of reagents. Studies on reagent (HMBATSC) concentration effect revealed that a minimum of 15 fold excess reagent to get maximum and stable absorbance for the complex. From the absorption spectra of [Cu (II) - HMBATSC] the molar absorptivity and sandell's sensitivity was found as $6.0 \times 10^{-3} \mathrm{~L} \cdot \mathrm{mol}^{-1} \mathrm{~cm}^{-1}$ and $0.011 \mu \mathrm{gcm} 2$. Various amounts of [Cu (II) - HMBATSC] were treated with suitable amounts of reagent by plotting the measured absorbance value of the prepared solutions against the concentration of $\mathrm{Cu}$ (II). From the calibration plot, it was observed that Beer's law was obeyed in the concentration range $0.254-2.542 \mu \mathrm{gml}^{-1}$ of $\mathrm{Cu}$ (II). The straight line obeys the equation $\mathrm{A}_{390}=0.6092 \mathrm{C}+0.0006$. The second derivative curves recorded (Fig.2) for experimental solutions showed the derivative amplitudes were measured at $428 \mathrm{~nm}$ for different concentrations of $\mathrm{Cu}$ (II) and plots were made between the amount of $\mathrm{Cu}$ (II) and the derivative amplitude. The plots were linear and obeyed beer's law in the range $0.064-4.066 \mu \mathrm{gml}^{-1}$ at $428 \mathrm{~nm}$. The effect of various cations and anions on the derivative amplitude was studied and it was noticed that all the ions that did not interfere in the zero order determinations of $\mathrm{Cu}$ (II) also did not interfere in second order derivative method. The composition, the possible geometry of $\mathrm{Cu}$ (II) complexes and the coordination sites of the ligand suggest the following possible structure for [Cu(II)HMBATSC] complex. The analytical and statistical data of direct and derivative method are presented in table

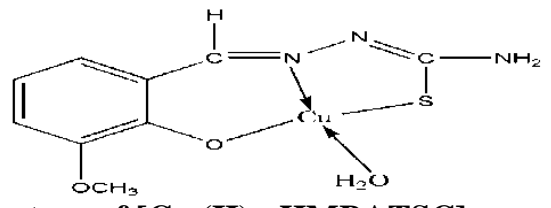

Structure of [Cu (II) - HMBATSC] complex 


\section{Applications}

The proposed direct spectrophotometric method was applied for the determination of copper in various water samples.

\section{Determination of $\mathrm{Cu}$ (II) spiked in natural water samples by spectrophotometric method}

Different water samples (distilled, tap water and lake water) were collected from various places in and around Anantapuramu , A.P., India. To $10 \mathrm{ml}$ aliquots of clear uncontaminated filtered water samples, 0.5 or $1.5 \mu \mathrm{gml}^{-1}$ of $\mathrm{Cu}$ (II) were added and the $\mathrm{pH}$ adjusted to 5.0. Concentration of $\mathrm{Cu}$ (II) was determined by spectrophotometrically and by atomic Absorption spectrometry(AAS), The results obtained by the reported method are comparable with those obtained by AAS method and are presented in table 2

\section{Analysis of $\mathrm{Cu}$ (II) in synthetic and real samples}

The usefulness of the derivative method developed by determining copper in various real samples of associated elements which are presented in table 3. The results obtained are in good agreement with those of certified values.

Table 3: Analysis of Synthetic mixtures and real samples

\begin{tabular}{|l|l|l|l|l|}
\hline $\begin{array}{l}\text { Name of the } \\
\text { sample }\end{array}$ & $\begin{array}{l}\text { Certified } \\
\text { value }\end{array}$ & $\begin{array}{l}\mathrm{Cu} \text { found } \\
\left(\mu \mathrm{gml}^{-1}\right)\end{array}$ & Relative error & Recovery (\%) \\
\hline Aluminium pins & 5.44 & 5.45 & -0.18 & 100.2 \\
\hline Aluminium chips & 4.07 & 4.05 & +0.50 & 99.5 \\
\hline
\end{tabular}

*Average of five determinations

Table 2: Determination of $\mathrm{Cu}$ (II) spiked in natural water samples by spectrophotometric method

\begin{tabular}{|l|l|l|l|l|l|l|}
\hline S.No & Type of water & $\begin{array}{l}\text { Cu (II) added } \\
\left(\mu \mathrm{gml}^{-1}\right)\end{array}$ & \multicolumn{2}{l|}{ Spectrophotometric method } & \multicolumn{2}{l|}{$\begin{array}{l}\text { AAS method } \\
(\mathrm{n}=2)\end{array}$} \\
\hline & & & $\begin{array}{l}\text { Found } \\
\left(\mu \mathrm{gml}^{-1}\right)\end{array}$ & $\begin{array}{l}\text { Recovery } \\
(\%)\end{array}$ & $\begin{array}{l}\text { Found } \\
\left(\mu \mathrm{gml}^{-1}\right)\end{array}$ & $\begin{array}{l}\text { Recovery } \\
(\%)\end{array}$ \\
\hline 1. & Distilled water & - & Not determined & - & Not determined & \\
\hline & & 0.5 & 0.489 & 97.80 & 0.485 & 97.80 \\
\hline & & 1.5 & 1.49 & 99.33 & 1.490 & 96.66 \\
\hline 2. & $\begin{array}{l}\text { Tap water } \\
\text { (Laboratory) }\end{array}$ & - & 2.3 & - & 2.5 & - \\
\hline & & 0.5 & 2.783 & 99.39 & 2.790 & 99.64 \\
\hline & & 1.5 & 3.491 & 99.74 & 3.495 & 99.85 \\
\hline & Lake water & - & 4.0 & - & 4.1 & - \\
\hline & & 0.5 & 4.448 & 99.84 & 4.590 & 99.78 \\
\hline
\end{tabular}

${ }^{*}$ Average of five determinations

\section{Conclusions}

Rapid color development, simplicity and selectivity are the advantages of the proposed method. The intensity of the colored species will not be affected by slight variation of the experimental parameters such as concentration of the reagent. The proposed method does not involve extraction, heating or any other stringent reaction conditions and offers the advantage of high color stability (48h). The commonly associated metal ions, especially Co (II), In (III) \& V(V) could be tolerated in considerable excess, which is an advantage over other reported reagents. The proposed method can be used as an alternative method for the determination of trace amounts of copper in water and real samples.

Table 1 : Analytical \& statistical data of direct and derivative method

\begin{tabular}{|c|c|c|}
\hline Parameter & Zero order & Second derivative method \\
\hline Wavelenth(nm) & 395 & 428 \\
\hline Beer's law range $\left(\mu \mathrm{gml}^{-1}\right)$ & $0.254-2.542$ & $0.064-4.066$ \\
\hline Sandell's sensitivity $\left(\mu \mathrm{g} \mathrm{cm}^{-2}\right)$ & $12.306 \times 10^{5}$ & - \\
\hline 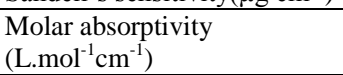 & $6.0 \times 10^{-3}$ & - \\
\hline Angular coefficient & 0.6092 & 0.442 \\
\hline Y intercept & 0.0006 & 0.029 \\
\hline Correlation coefficient(r) & 0.9999 & 0.998 \\
\hline Standard deviation(s) & 0.0016 & 0.030 \\
\hline Detection limit $\left(\mu \mathrm{gml}^{-1}\right)$ & 0.020 & 0.2058 \\
\hline Determination limit $\left(\mu \mathrm{gml}^{-1}\right)$ & 0.061 & 0.614 \\
\hline $\operatorname{RSD}(\%)$ & 0.48 & 8.99 \\
\hline Complex ratio & $1: 1$ & - \\
\hline
\end{tabular}




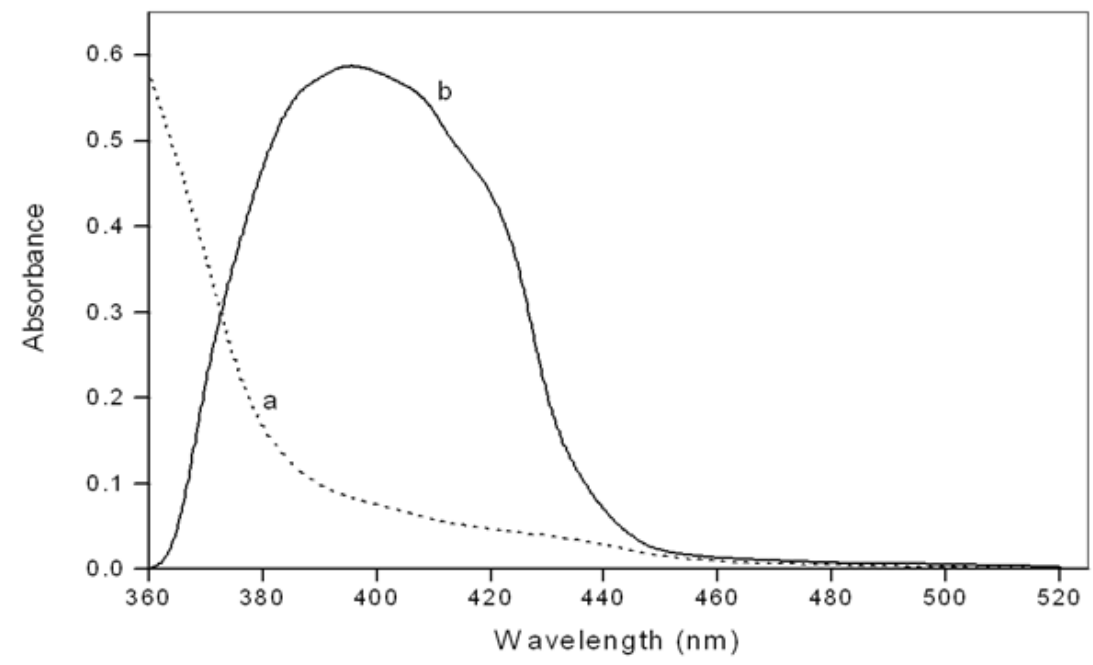

Fig 1: Absorption spectra of

a) HMBATSC vs Buffer Blank

b) [Cu (II) - HMBATSC] vs Reagent blank $\mathrm{Cu}$ (II) $=4 \mathrm{X}^{-4} 0^{-4}$ HMBATSC $=2 \times 10^{-3} \mathrm{pH}=5$

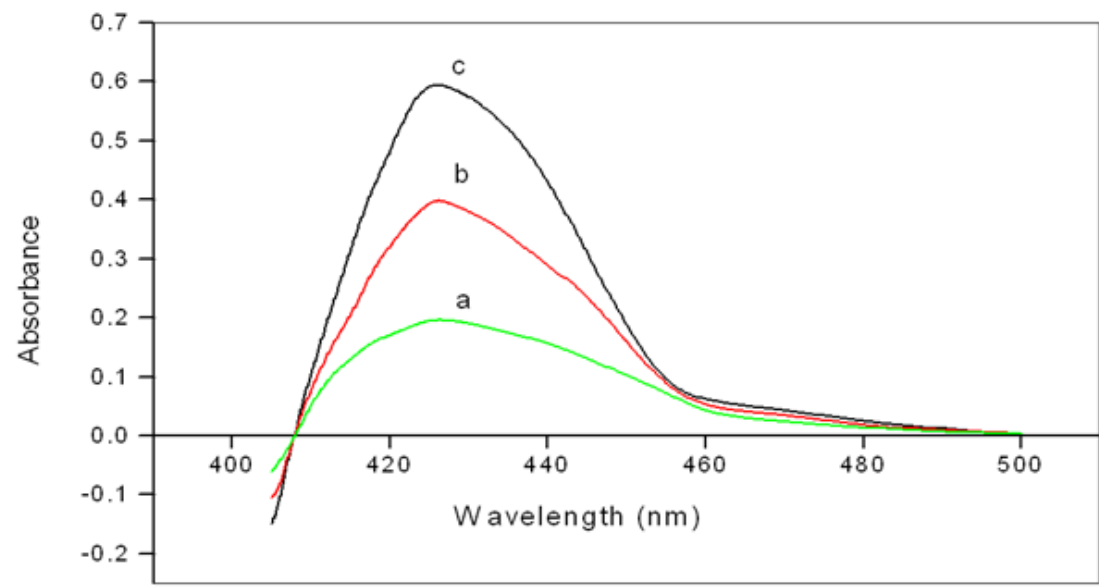

Fig 2: Second order Derivative Spectra of

\section{Cu(II) - HMBATSC vs Reagent blank}

$\mathrm{Cu}(\mathrm{II})\left[\mu \mathrm{g} \mathrm{ml}^{-1}\right]=$ (i) $0.3 \mathrm{ml}$, (ii) $0.6 \mathrm{ml}$, (iii) $0.9 \mathrm{ml}$

\section{References}

[1]. Copper toxicity in the general population. Clin Neurophysyol 121(4), 2010,459-60.

[2]. Z. Marczenko, Spectrophotometric determination of metal ions, Ellis, Hardwood Ltd, England, 239, 1976.

[3]. Z.Marczenko, Spectrophotometric determination of elements, Hardwood Ltd, Chichester, 1986.

[4]. S.F Snell, Photometric and plurometric methods of analysis (Metals), P.F.M.A. Wiley, Interscience Pub. Part 1, Chapter 5, 141, 1978.

[5]. R. Lobinski, Z. Marczenko, Crit. Rev.Anal.Chem, 23(1), 55, 1992.

[6]. C.R.Elloit, P.F Preston and Thompson. J.H, Analyst, 84, 237, 1959.

[7]. Z. Marczenko, Micro Chim. Acta, 281, 1965.

[8]. G. Brown and R.K Rohde, Anal. Chem, 38, 911, 1966.

[9]. R.K, Middleton, Analyst, 90,234, 1965.

[10]. R. Capelle, Chim, Anal.(Paris) 42, 69,1960.

[11]. O. Saichiro, W. Kusinsilko and Y. Yukiehi and Bunsiki kagaku, 14, 339, 1965.

[12]. D.Gopalakrishna, N. Devanna. K.B.Chandrasekhar, I.J.of Analytical and bioanalytical chemistry., 1(1), 2011, 19-24

[13]. C. Malathi, T.Sreenivasulu Reddy, International Journal of Analytical \& Bioanalytical chemistry., 2(3), 2012, 175-178.

[14]. M. Jamaluddin Ahmed and Tasnima Zannat, Pak. J. Anal. Environ.Chem, 13(1), 2012 22- 35.

[15]. P.V.Chalapathi., B.Prathima, Y.SubbaRao, K.Janardhan Reddy, G.N.Ramesh and D.V.Ramana Reddy, J.Chem. pharma. Res., 3(2), 2011, 534-549.

[16]. M. Barazandeh Tehrani., S.M.S. Mirkamali., E. Souri and A. Foroumadi., Asian Journal of Chemistry, 24(10), 2012, 4517-4521

[17]. P. Ratnamala, R.S. Sonawane, Lokhande, M. Utkarsha Chavan., International of chemistry, Physics and astronomy, 9(1), 2013, 1-6. 
[18]. Admasu Daniel, D .Najarjuna Reddy and K.Mekonnen, Spectrophotometric determination of Cu(II) in soil and vegetabe sampes using heterocyclic thiosemicarbazone, springer plus.

[19]. P.Nityanandakumar, G.Trivikram Reddy, A.V.R Reddy,Spectrophotometric determination of Cu (II) in ground water and food samples, Journal of chemical and pharmaceutical research,7(2), 2015, 581-590.

[20]. M.Rohani Moghadam, A Darehkordi, Simultaneous spectrophotometric determination of copper, cobalt, nickel and iron in foodstuffs and vegetables with a bis thiosemocarbazone ligand using chemometric approaches, Food chem., 2016, jul 8.

[21]. K.shanthalakshmi and B.Muralidgar Rao, spectrophotometric determination of copper using o-vanildine-2-amino-4ethylbenzothiazole as a chromic reagent, Der pharmacia Lettre, 7(10), 2015, 281-284.

[22]. Y.K. Patil , R.S. Lokhande and C.Y.Patil,extractive spectrophotometric determination of Copper(II) by using 2-hydroxy-3-methoxy benzaldehyde thiosemicarbazone as an analytical reagent, World journal of [pharmacy and pharmaceutical sciences.,5(2), 2016, 965-70.

[23]. A.I., Vogel, A Text book of Quantitative Inorganic Analysis, $3^{\text {rd }}$ Edn., ELBS and Longman,p.309,1962.

[24]. Kerser sozgen, Esma Tutem, Talanta, 62(5), 2004, 971-975. 